\title{
Efficient strategy for controlling postoperative hemorrhage in total knee arthroplasty
}

\author{
Hideyuki Sasanuma $\cdot$ Hitoshi Sekiya $\cdot$ \\ Kenzou Takatoku $\cdot$ Hisashi Takada • \\ Naoya Sugimoto $\cdot$ Yuichi Hoshino
}

Received: 14 October 2009/Accepted: 31 August 2010/Published online: 18 September 2010

(C) The Author(s) 2010. This article is published with open access at Springerlink.com

\begin{abstract}
Purpose The objective of the present study was to compare the intraoperative use of tranexamic acid (TNA) plus intra-articular diluted-epinephrine (DEP) with preoperative autologous blood donations and transfusions in reducing an allogeneic blood transfusion (ABT) in primary unilateral total knee arthroplasty (TKA).

Methods Patients $(n=133)$ treated with unilateral primary TKA were divided into three groups retrospectively: patients administered autologous blood transfusions were assigned to group A $(n=51)$; patients administered preoperative injections of TNA and postoperative intra-articular injections of DEP were assigned to group B $(n=42)$; and patients treated with the drain-clamp method in addition to injections of TNA and DEP were assigned to group $\mathrm{C}(n=40)$. The rate of avoidance of ABTs, postoperative blood loss, and complications (DVT/PE, skin problems) were examined.

Results The differences among the three groups were not significant in terms of the proportion of patients requiring no ABTs (94\% in group A, 93\% in group B and 95\% in group C, n.s.). The total blood loss calculated was $1,140 \pm 451 \mathrm{ml}$, $852 \pm 343 \mathrm{ml}$, and $850 \pm 296 \mathrm{ml}$, respectively (group $\mathrm{B}>\mathrm{A}$, group $\mathrm{C}>\mathrm{A}, P=0.0009)$. The significant complications were not observed in three groups.

Conclusion The results of the study showed that the TNA plus DEP combination exerted a comparable effect with preoperative autologous blood transfusion in avoiding
\end{abstract}

H. Sasanuma ( $₫) \cdot$ H. Sekiya $\cdot$ K. Takatoku $\cdot$ H. Takada N. Sugimoto - Y. Hoshino

Department of Orthopaedic Surgery, Jichi Medical University,

3311-1 Yakushiji, Shimotsuke, Tochigi 3290498, Japan

e-mail: sasakou@pop12.odn.ne.jp
ABTs in unilateral primary TKA. Considering several problems of preoperative autologous blood donation, the use of TNA plus DEP is recommended. In addition, it is highly possible that allogeneic blood transfusions can be avoided for patients with preoperative $\mathrm{Hb}$ values $\geq 10.5$ using the method described in this study, and the need for preoperative autologous blood donations can be decreased.

Keywords Total knee arthroplasty - Allogeneic blood transfusion - Tranexamic acid - Epinephrine .

Autologous blood donation

\section{Introduction}

Blood loss is unavoidable after total knee arthroplasty (TKA). In recent years, a growing number of effective agents and new techniques for avoiding allogeneic blood transfusions (ABT) have been reported because ABTs may lead to serious complications [10]. However, the safest and most efficient method has not been identified.

As a measure to reduce the blood transfusions and blood loss associated with TKA, preoperative autologous blood donations have been used since 1990. However, the procedure is associated with the problems of troublesome administrative tasks, high costs, contraindications in patients with anemia, and the limited storage period. Some studies reported that an excessive volume of blood was stored [4, 5, 7, 9, 11, 23].

As a strategy for reducing blood loss, drain clamping has been combined with intravenous or intra-articular administration of tranexamic acid (TNA) and intra-articular injection of diluted-epinephrine (DEP) since approximately 1995, and the preventive effect on blood loss is well documented [3, 8, 25]. 
The objective of the present study was to compare the rate of avoidance of ABTs combined with the use of TNA and DEP in preoperative autologous blood donations and develop a protocol for safe ABTs in TKA by combining TNA and DEP, based on the results of the comparison. The proposed hypothesis was that a means of using TNA plus DEP would increase the proportion of patients who would not require $\mathrm{ABT}$ s rather than preoperative autologous blood donations.

\section{Materials and methods}

This study was a non-randomized, retrospective study that included 133 knees undergoing unilateral primary TKA from 2004 through 2007. All surgeries were performed by a single surgeon $(\mathrm{SH})$. General anesthesia and continuous femoral nerve blocks were used. The implant used in all patients was the Scorpio $\mathrm{NRG}^{\circledR}$ posterior-stabilized type (Stryker Howmedica Osteonics, Allendale, NJ). In all patients, the patella was replaced, and all components were fixed with cement. Surgery was performed under tourniquet control. After midline skin incision, a medial parapatellar approach was utilized. Depending on the study period, three measures were implemented to reduce blood loss and blood transfusions. Exclusion criteria were known allergies to tranexamic acid, ASA-IV physical status or higher, severe ischemia and/or heart valve disease, history of thromboembolic episodes, known coagulopathy, and renal dysfunction (serum creatinine concentration, $>1.5 \mathrm{mg} / \mathrm{dL})$.

(1) The autologous blood transfusion group (group A, $n=51)$

During the early study period, autologous blood was collected on preoperative day 4 or earlier (mean, 2.2 units). Indications for preoperative autologous blood donations were based on the Standards for Preoperative Autologous Blood Donations (2007) developed by the Japanese Society of Autologous Blood Transfusions. Patients had to have a blood hemoglobin ( $\mathrm{Hb})$ level of $11.0 \mathrm{~g} / \mathrm{dL}$ or more or a hematocrit level of $33 \%$ or more. No age limit was established. Oral iron preparations were administered at a daily dose of $200 \mathrm{mg}$ for 1 week before initial blood collection. When the collection of 4 or more units of blood took 1 week or longer, 24,000 units of recombinant human erythropoietin $\left(\mathrm{ESPO}^{\circledR}\right.$, epoetinum alfa, Kyowa Kirin Co. Ltd., Tokyo, Japan) was administered subcutaneously. On postoperative day 1, all patients received autologous blood transfusions. After surgery, a drain was inserted, and no specific postoperative blood loss was prevented.
(2) The intravenous TNA plus intra-articular DEP group (group $\mathrm{B}, n=42$ )

Twenty minutes before surgery, $1,000 \mathrm{mg}$ of TNA (Transamin $10 \%{ }^{\circledR}$, Daiichi-Sankyo Co. Ltd., Tokyo, Japan) was administered intravenously. After wound closure, $50 \mathrm{~mL}$ of epinephrine diluted to 1:200,000 was injected intra-articularly without drain insertion.

(3) The intravenous TNA plus intra-articular DEP plus drain-clamping group (group C, $n=40$ )

As in the case of group B, TNA was administered intravenously. When the wound was closed, however, an intra-articular drain was inserted, and $50 \mathrm{~mL}$ of epinephrine diluted to 1:200,000 was injected intra-articularly. The suction drain was clamped for the first $3 \mathrm{~h}$ and then unclamped in group C. The drain was removed $48 \mathrm{~h}$ later in groups $\mathrm{A}$ and $\mathrm{C}$. As part of the postoperative care for the three groups, continuous passive movement was started on postoperative day 3 , and standing and full-weight-bearing walking were allowed.

Bleeding-related outcome measures included changes in $\mathrm{Hb}$, drained blood loss (group A and C), total postoperative blood loss, proportion of patients requiring no allogenic blood transfusions, and complications related to the prevention of blood loss. Hb levels were measured on the day before surgery and postoperative days 1, 4, and 7. A formula proposed by Nadler et al. [20] and Sehat et al. [24] was used to calculate the total postoperative blood loss. The loss of $\mathrm{Hb}$ was then estimated according to the following formula:

$$
\begin{aligned}
\text { Blood volume }(1)= & \text { height }(\mathrm{m})^{3} \times 0.356 \\
& + \text { body weight }(\mathrm{kg}) \times 0.033 \\
& +0.183(\text { woman }) \\
= & \text { height }(\mathrm{m})^{3} \times 0.367 \\
& + \text { body weight }(\mathrm{kg}) \\
& \times 0.032+0.604(\text { man })
\end{aligned}
$$

$\mathrm{Hb}_{\text {loss }}(\mathrm{g})=$ Blood volume $\times 10 \times\left(\mathrm{Hb}_{\mathrm{i}}-\mathrm{Hb}_{\text {fin }}\right)+\mathrm{Hb}_{\mathrm{t}}$

Total blood loss $(\mathrm{ml})=\mathrm{Hb}_{\text {loss }} / \mathrm{Hb}_{\mathrm{i}} \times 100$

where $\mathrm{Hb}_{\text {loss }}(\mathrm{g})$ was the amount of $\mathrm{Hb}$ lost, $\mathrm{Hb}_{\mathrm{i}}(\mathrm{g} / \mathrm{dl})$ was the $\mathrm{Hb}$ concentration before surgery, $\mathrm{Hb}_{\text {fin }}(\mathrm{g} / \mathrm{dl})$ was the $\mathrm{Hb}$ concentration on postoperative day 4 or 7 (whichever was lower), and $\mathrm{Hb}_{\mathrm{t}}$ (g) was the total amount of allogeneic and autologous $\mathrm{Hb}$ transfused.

To investigate the influence on the development of postoperative deep vein thrombosis (DVT) and pulmonary embolisms (PE), contrast-enhanced computed tomography (CT) was performed in patients with a D-dimer level of $20 \mu \mathrm{g} / \mathrm{mL}$ or more on postoperative days $1,4,7$, and 14 
and those with clinical symptoms suggestive of DVT. Images were read by two radiologists. Patients with a diagnosis of DVT or PE and those with persistently elevated D-dimer levels received continuous heparin infusion and oral warfarin therapy. Oral warfarin was continued for 3 months. Oral therapy was controlled to achieve a target INR of 2-3. On postoperative day 14, patients were also examined for postoperative skin disorders (skin necrosis, skin loss, and superficial infections).

\section{Statistical analysis}

ANOVA and an unpaired $t$-test were used to analyze parametric data, whereas a chi-square test among the three groups was used for non-parametric data. When a significant difference was found, groups were compared using the Bonferroni method. A $P$-value of 0.05 or less was considered a significant difference.

\section{Results}

Among the three groups, there were no significant differences in patient characteristics of gender, age, underlying disease, body weight, and height (Table 1). At any point in time (preoperative day and postoperative day 1, 4, or 7), there were no significant differences among the three groups (Table 2, postoperative $\mathrm{Hb}$ ). The postoperative drained blood loss (Table 2) was $535 \pm 212 \mathrm{~mL}$ and $328 \pm 109 \mathrm{~mL}$ in groups A and C, respectively, indicating a significant reduction in group $\mathrm{C}(P=0.00001)$. As shown in Fig. 1, the total postoperative blood loss in groups $\mathrm{B}$ and $\mathrm{C}$ was significantly less than that in group $\mathrm{A}$ $(P=0.0009)$. In Table 2 , the proportion of patients requiring no ABTs was 94\% (48/51) in group A, 93\% (39/ 42 ) in group $B$, and $95 \%$ (38/40) in group $C$, with no significant differences among the three groups. Finally, in the development of DVT and PE (Table 3), there were no significant differences among the three groups. All cases of PE were asymptomatic. As for skin conditions (Table 3),

Table 1 Patient characteristics

\begin{tabular}{lllll}
\hline & $\begin{array}{l}\text { Group A } \\
(n=51)\end{array}$ & $\begin{array}{l}\text { Group B } \\
(n=42)\end{array}$ & $\begin{array}{l}\text { Group C } \\
(n=40)\end{array}$ & $P$ value \\
\hline Gender (male/female) & $4 / 47$ & $6 / 36$ & $5 / 35$ & n.s. \\
Age (year) & $70 \pm 10$ & $68 \pm 9$ & $65 \pm 12$ & n.s. \\
Disease (RA/OA) & $16 / 35$ & $20 / 22$ & $18 / 22$ & n.s. \\
Body weight (kg) & $55 \pm 10$ & $55 \pm 11$ & $56 \pm 9.5$ & n.s. \\
Height $(\mathrm{cm})$ & $149 \pm 10$ & $150 \pm 8.7$ & $151 \pm 7.9$ & n.s. \\
\hline
\end{tabular}

Values are expressed as mean $\pm \mathrm{SD}$. There was no significant difference in every category

$R A$ rheumatoid arthritis, $O A$ osteoarthritis
Table 2 Hemoglobin $(\mathrm{Hb})$ level concentrations before and after operation and drained blood loss, transfusion requirements

\begin{tabular}{lllll}
\hline & Group A & Group B & Group C & $P$ value \\
\hline $\begin{array}{l}\text { Preoperative } \mathrm{Hb} \\
\text { (g/dl) }\end{array}$ & $12.0 \pm 1.0$ & $12.2 \pm 1.6$ & $12.4 \pm 1.4$ & n.s. \\
Postoperative Hb (g/dl) & & & & \\
Day 1 & $9.4 \pm 1.5$ & $10.1 \pm 1.3$ & $10.0 \pm 1.2$ & n.s. \\
Day 4 & $9.4 \pm 1.3$ & $9.3 \pm 1.2$ & $8.9 \pm 1.5$ & n.s. \\
Day 7 & $9.6 \pm 1.4$ & $9.5 \pm 1.3$ & $9.1 \pm 1.6$ & n.s. \\
Fall in Hb (g/dl) & & & & \\
Preop-day 1 & & $2.3 \pm 1.4$ & $2.4 \pm 0.9$ & \\
$\begin{array}{l}\text { Day 1-day 4 } \\
\begin{array}{l}\text { Drained blood loss } \\
\text { (ml) }\end{array}\end{array}$ & $535 \pm 212$ & & $328 \pm 109$ & 0.00001 \\
Allogeneic transfusion needs & & & \\
$\begin{array}{l}\text { Number of patients } \\
\text { Avoidance rate (\%) }\end{array}$ & 94 & 3 & 2 & n.s. \\
\hline
\end{tabular}

Values are expressed as mean $\pm \mathrm{SD}$

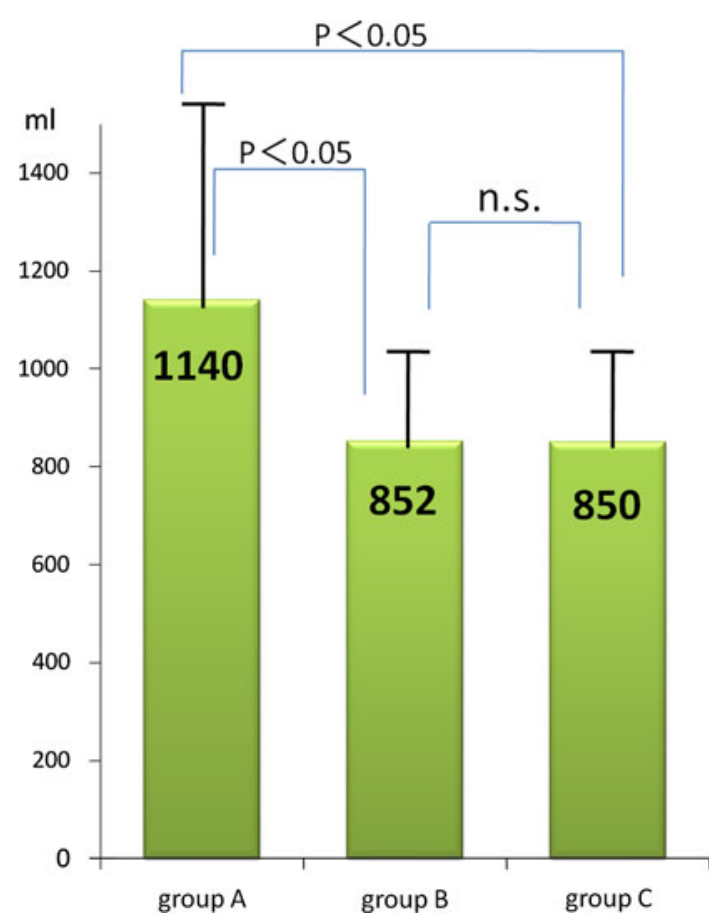

Fig. 1 Total postoperative blood loss

there were no significant differences among the three groups for complications in the wound area.

\section{Discussion}

The most important finding of the present study was that the rate of avoidance of ABT in TNA plus the combination of DEP was similar to that of preoperative autologous 
Table 3 Postoperative complications

\begin{tabular}{lclll}
\hline & Group A & Group B & Group C & $P$ value \\
\hline Number of DVT & 10 & 7 & 9 & n.s. \\
Number of PE & 1 & 1 & 2 & n.s. \\
Number of skin trouble & 2 & 1 & 1 & n.s. \\
$\quad$ (necrosis, loss, infection) & & & & \\
\hline
\end{tabular}

Values are expressed as mean $\pm \mathrm{SD}$ or number

$D V T$ deep venous thrombosis, $P E$ pulmonary embolism

blood transfusions. Considering the several problems of preoperative autologous blood donations $[4,5,7,9,11$, 23], DEP plus TNA can be a more effective method of handling postoperative blood loss in avoiding ABT.

Since the reports by Benoni et al. [3], many groups have reported the usefulness of TNA in TKA [1, 6, 19, 21]. Cid et al. [8] performed a meta-analysis of the use of TNA in reducing blood loss in TKA and reported that the use of TNA significantly reduced the number of patients requiring blood transfusions and the volume of each blood transfusion. Although complications due to thrombosis caused by fibrinolytic inhibition have been a concern, there have been no reports of such complications [25]. Similarly, there were no significant differences in the incidence of DVT or PE among the three groups.

The effect of drain clamping plus DEP after TKA has been controversial. Anderson et al. [2] and Gasparini et al. [12] reported that intra-articular injections of DEP decreased blood loss after TKA. On the other hand, Malone et al. [16] reported that intra-articular injections of DEP were not effective. Some reports suggest that long periods of DEP plus drain clamping increased the development of skin lesions $[12,16]$. In the current study, the hemostatic effect of intra-articular injection of DEP alone and the incidence of complications were not compared. However, skin disorders did not occur more frequently in group B in which no drain was inserted. Actually, swelling of the thigh and lower leg during the first two weeks after surgery was more severe in group B (no drain inserted) than in group C. Thus, measures to reduce blood are now implemented as in group C.

Some studies have recently stressed the importance of establishing an ABT protocol as a way to reduce postoperative blood loss and blood transfusions [14, 15, 17]. In other studies, it has been reported that the preoperative $\mathrm{Hb}$ level is a risk factor for postoperative blood transfusions $[13,14,18,22]$. Predicting the lowest postoperative $\mathrm{Hb}$ level from the preoperative $\mathrm{Hb}$ level, Jeffery et al. [15] developed and implemented an algorithm for ABTs. The authors reported a $14 \%$ reduction in the rate of blood transfusions. Analysis of the change in $\mathrm{Hb}$ from baseline in patients showed that the Hb levels in groups
B and C decreased by 2.3 and $2.4 \mathrm{~g} / \mathrm{dL}$, respectively, on postoperative day 1 and further decreased by 1.0 and $1.1 \mathrm{~g} / \mathrm{dL}$, respectively, on postoperative day 4 . Thus, there were overall decreases of 3.3 and $3.5 \mathrm{~g} / \mathrm{dL}$ in groups B and C, respectively (Table 2). The guidelines from the blood transfusion committee in the hospital indicate that the $\mathrm{Hb}$ level at which ABTs are indicated is $7-8 \mathrm{~g} / \mathrm{dL}$ in patients without cardiovascular and other systemic symptoms who undergo elective orthopedic surgery. Given that an $\mathrm{Hb}$ level of $7 \mathrm{~g} / \mathrm{dL}$ or less is an indication of ABTs, concomitant use of intravenous TNA and postoperative intra-articular injections of DEP potentially eliminates the need for blood transfusions in patients with a preoperative $\mathrm{Hb}$ level of $10.5 \mathrm{~g} / \mathrm{dL}$ or more. An algorithm was developed: when the $\mathrm{Hb}$ level on postoperative day 1 decreases to $7-8 \mathrm{~g} / \mathrm{dL}$, ABTs may be necessary depending on the patient's condition. When the $\mathrm{Hb}$ level on postoperative day 1 ranges from 8 to $9 \mathrm{~g} / \mathrm{dL}$, decisions are made on the basis of hematologic test results on postoperative day 4 (Fig. 2). Treatment is now provided according to this algorithm without preoperative autologous blood donations.

The present study had several limitations. This was a retrospective study. Although there were no differences in patient characteristics among the three groups, selection bias was not completely excluded in this study. The synergistic effect of administration of TNA or intra-articular DEP was not investigated. Both the administration of TNA and intra-articular DEP reduced postoperative blood loss after tourniquet release, and further studies (RCTs) are needed to determine dosage and administration. The clinical relevance of this study was that the combination of TNA and DEP might supplant autologous blood transfusions in order to reduce ABTs in unilateral primary TKA.

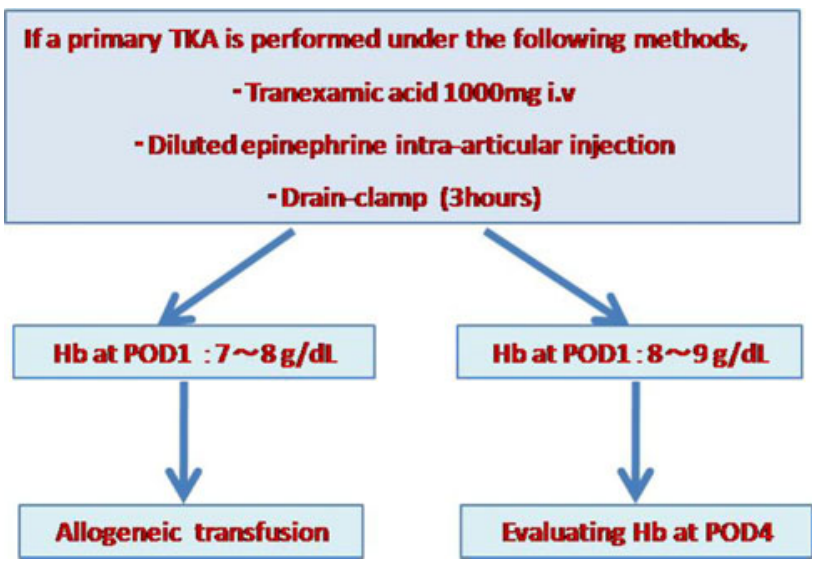

Fig. 2 Our recommended allogeneic blood transfusion protocol in primary TKAs 


\section{Conclusion}

The results of the current study demonstrated that the TNA plus DEP combination exerted a comparable effect with preoperative autologous blood transfusions in avoiding ABTs in unilateral primary TKA. Considering the several problems of preoperative autologous blood donation, the use of TNA and DEP is recommended to prevent blood loss. In addition, allogeneic blood transfusions may be avoided for patients with $\mathrm{Hb}$ values $\geq 10.5$ by using this method, and the need for preoperative autologous blood donations can be decreased.

Acknowledgments The authors would like to express their gratitude to Eiryo Kawakami, MD, and Daisuke Tamura, MD, for editing the manuscript and for editorial assistance.

Open Access This article is distributed under the terms of the Creative Commons Attribution Noncommercial License which permits any noncommercial use, distribution, and reproduction in any medium, provided the original author(s) and source are credited.

\section{References}

1. Alvarez JC, Santiveri FX, Ramos I, Vela E (2008) Tranexamic acid reduces blood transfusion in total knee arthroplasty even when a blood conservation program is applied. Transfusion 48:519-525

2. Anderson LA, Engel GM, Bruckner JD, Stoddard GJ (2009) Reduced blood loss after total knee arthroplasty with local injection of bupivacaine and epinephrine. J Knee Surg 22: 130-136

3. Benoni G, Fredin H (1996) Fibrinolytic inhibition with tranexamic acid reduces blood loss and blood transfusion after knee arthroplasty: a prospective, randomised, double-blind study of 86 patients. J Bone Joint Surg Br 78:434-440

4. Bierbaum BE, Callaghan JJ, Galante JO, Rubash HE, Tooms RE, Welch RB (1999) An analysis of blood management in patients having a total hip or knee arthroplasty. J Bone Joint Surg Am 81:2-10

5. Billote DB, Glisson SN, Green D, Wixson RL (2002) A prospective, randomized study of preoperative autologous donation for hip replacement surgery. J Bone Joint Surg Am 84:1299-1304

6. Camarasa MA, Olle G, Serra-Prat M, Martin A (2006) Efficacy of aminocaproic, tranexamic acids in the control of bleeding during total knee replacement: a randomized trial. $\mathrm{Br} \mathrm{J}$ Anaesth 96:576-582

7. Chun TY, Martin S, Leptor H (1997) Preoperative recombinant human erythropoietin injection versus preoperative autologous blood donation in patients undergoing radical retropubic prostatectomy. Urology 50:727-732

8. Cid J, Lozano M (2005) Tranexamic acid reduces allogeneic red cell transfusions in patients undergoing total knee arthroplasty: results of a meta-analysis of randomized controlled trials. Transfusion 45:1302-1307

9. Cohen JA, Brecher ME (1995) Preoperative autologous blood donation: benefit or detriment? A mathematical analysis. Transfusion 35:640-644

10. Earnshaw P (2001) Blood conversation in orthopaedic surgery: the role of epoetin. Int Orthop 25:273-278

11. Ecthason J, Petz L, Keeler E, Calhoun L, Kleinman S, Snider C, Fink A, Brook R (1995) The cost effectiveness of preoperative autologous donations. N Engl J Med 332:719-724

12. Gasparini P, Papaleo P, Pola S, Cerciello E, Pola C (2006) Local infusion of norepinephrine reduces blood losses and need of transfusion in total knee arthroplasty international orthopaedics. SICOT 30:253-256

13. Hatzidakis AM, Mendlick RM, McKillip T, Reddy RL (2000) Preoperative autologous donation for total joint arthroplasty. An analysis of risk factors for allogenic transfusion. J Bone Joint Surg 82:89-100

14. Helm AT, Karski MT, Parsons SJ, Sampath JS (2003) A strategy for reducing blood-transfusion requirements in elective orthopaedic surgery. Audit of an algorithm for arthroplasty of the lower limb. J Bone Joint Surg Br 85:484-489

15. Jeffery LP, Timothy JH, Donald RE (2004) A blood-conservation algorithm to reduce blood transfusions after total hip and knee arthroplasty. J Bone Joint Surg Am 86:1512-1518

16. Malone KJ, Matuszak S, Mayo D, Greene P (2009) The effect of intra-articular epinephrine lavage on blood loss following total knee arthroplasty. Orthopedics 32:100-103

17. Martinez V, Monsaingeon-Lion A, Cherif K, Judet T (2007) Transfusion strategy for primary knee and hip arthroplasty: impact of an algorithm to lower transfusion rates and hospital costs. Br J Anaesth 99:794-800

18. Mesa-Romas F, Mesa-Romas M, Maquieira-Canosa C (2008) Predictors for blood transfusion following total knee Arthroplasty: a prospective randomized study. Acta Orthop Belg 74:83-89

19. Molloy DO, Archbold HA, Ogonda L, McConway J (2007) Comparison of topical fibrin spray and tranexamic acid on blood loss after total knee replacement: a prospective, randomized controlled trial. J Bone Joint Surg Br 89:306-309

20. Nadler SB, Hidalgo JU, Blouch T (1962) Prediction of blood volume in normal human adults. Surgery 51:224-232

21. Ralley FE, Berta D, Binns V, Howard J (2010) One intraoperative dose of tranexamic acid for patients having primary hip or knee arthroplasty. Clin Orthop Relat Res 468:1905-1911

22. Salido JA, Marín LA, Gómez LA, Zorrilla P, Martínez C (2002) Preoperative hemoglobin levels and the need for transfusion after prosthetic hip and knee surgery: analysis of predictive factors. J Bone Joint Surg Am 84:216-220

23. Spahn DR, Casutt M (2000) Eliminating blood transfusion: new aspects and perspectives. Anesthesiology 93:242-255

24. Sehat KR, Evans RL, Newman JH (2004) Hidden blood loss following hip and knee arthroplasty. Correct management of blood loss should take hidden loss into account. J Bone Joint Surg Br 86:561-565

25. Tanaka N, Sakahashi H, Sato E, Hirose K, Ishima T, Ishii S (2001) Timing of the administration of tranexamic acid for maximum reduction in blood loss in arthroplasty of the knee. J Bone Joint Surg Br 83:702-705 